\title{
A NEW ECONOMIC MODEL IS THE KEY TO A GLOBAL DIVERSITY INCLUSION AND FAIRNESS
}

Dr. Patrizia Legovini

How do we define progress? How do we define human development? Or can we speak about an overall development with a global overview? Human progress and development have till today been based on an economical model, which is and has always been one of exploitation and ripping off resources from the ones who could not defend themselves. Furthermore we have always thought that resources were never-ending and that the planet was big enough to allow us to take advantage of it. This model is no more sustainable, considering that some of our key resources like water, air and, room are given and we cannot produce them. We also have to consider that our footprint today affects all other beings and the future generations for many centuries to come. Let's just think about the Roman deforestation of Europe, which is still visible today. It is therefore obvious that we need to develop and adopt a new paradigm. To this extent I would like to take the chance to introduce my view: first of all let's forget about the pyramid where men sit up top and all other living creatures down below, we are one among many and not "the one".

So how to change culture and who can do it? Like any lasting change on a global scale it needs leadership commitment, consistency, persistency, and communication (national and international), which is the one factor most people under-estimate and under-leverage. Remember: If you want to change attitudes, start with a change in behaviour (William Glaser, 2014). So take spreading a religion as an example for a cultural change and simply substitute "the faith" with a new idea you want to spread: you grow the 
faith in your community by talking about it - like the stories of miracles experienced by believers; you convert non-believers to believers by talking about your faith outside your community (with suppliers, customers, partners, peers) - like missionaries do when they go out to convert the world; you show with your behaviour the path to be followed - like a committed priest. Key people or enablers need to become missionaries for innovation that will lead to the change in culture we want to implement.

A good example in communication to animal related topics comes from the Nobel Prize winner economist and professor at Stanford and Harvard universities, Alvin Roth. In an interview given to Time Magazine he predicts a rise in veganism and a so called growing "repugnance" towards the consumption of meat and dairy products in the overall population, as a well define trend (Joel Stein, Time Magazine, 2014). To support his theory that meat eating might become repugnant to the general population, Mr. Roth talks about the state of the art of horse meat. For example in the State of California, it is illegal to sell horse meat for human consumption; it is not illegal though to kill horses in California, because it is assumed that there might be circumstances where putting down a horse is more humane than letting it suffer. The Law passed in 1998 when the Californians decided it is considered "repugnant" to eat horse meat, so much that it was declared against the law. So that change in attitude happened both recently and relatively suddenly. ${ }^{1}$

Roth's research takes into consideration the concept of "repugnance" as a driving market force; "repugnance" means the public rejects an idea as no longer acceptable in society. He takes as an example the slave market:

"Once people became repugnant to trading and owning slaves, the slave market collapsed - but we have settled, universally, that it is a good thing. A good economic model isn't just one where people can buy or sell what they want; it is about increasing welfare (utility). We decided that

\footnotetext{
${ }^{1}$ Kim, Nobel Prize Winner Alvin Roth on Future of Food <http://www.peacefuldumpling.com/exclusiveinterview-nobel-prize-winner-alvin-roth-on-future-of-food>
} 
salves have rights, and that their welfare matters more than the frustrated wants of the would be slave owner." ${ }^{2}$

Can this be compared to animals? What about the issue of animal rights and welfare vs. the habits of meat eaters? Mr. Roth reasons that, as knowledge of factory farming (cruelty, deprivation, violence, etc.) and awareness regarding ethical issues of health of all the actors involved in this process become more widespread, it may just happen that meat eating will rapidly become the exception, and not the rule or norm (Joel Stein, Time Magazine, 2014).

"Factory farming rose at a time when we were worried about feeding a large number of the population. Fortunately, in America we are no longer worried about malnutrition. Instead, we are now concerned about chickens being abused. So our welfare focus has shifted - and insofar as economics deals with increasing welfare (utility), factory farming can be seen as an economic problem." ${ }^{3}$

Let's go back to the first point I was trying to assess: can't we just consider ourselves as living beings among other living beings, as simple as that? Why do we have the perception of having power, exploitation and aggressive attitude towards all other creatures? According to Charles Darwin, nothing exists for itself alone, but only in relation to other forms of life. The most, or better, our most difficult challenge is the world of human indifference. For the vast majority of people still animals have no rights. We are as in the novel Animal Farm by George Orwell (published in 1945) thinking that some animals are more equal than others. This refers not only to the original plot but also to the reality nowadays. The problem is not only centred on intolerant people, but also on the passive,

\footnotetext{
${ }^{2}$ Kim, Nobel Prize Winner Alvin Roth on Future of Food <http://www.peacefuldumpling.com/exclusiveinterview-nobel-prize-winner-alvin-roth-on-future-of-food>

${ }^{3}$ Kim, Nobel Prize Winner Alvin Roth on Future of Food <http://www.peacefuldumpling.com/exclusiveinterview-nobel-prize-winner-alvin-roth-on-future-of-food>
} 
disinterested, and misinformed ones, who want to shrug off all responsibility from themselves and shift it to all the other actors (companies, distributors, retailers, peers, etc.). For example when we go to the supermarket we rely on the work of those, who put the items on the shelf for us, but we do not fully inform ourselves on what we are buying. We as consumers have the power to shift the means of production and sale, but we need to structure an organization to lobby and steer the process of all living being's welfare in an ethical direction. We have the power to spend our money in the right way and it is a BIG power, e.g. when we decide to buy animal testing free products, therefore shifting the demand.

Various examples in history have shown us that a small and slender body of determined spirits, fired by an unquenchable faith in their mission, can alter the course of rooted practices. Just think about women's right to vote, the universal right to education, the UN Convention on the Rights of the Child, the rights for homosexuals, and why not the exclusion of animals from the categorization of things in several civil codes. To this extent there are so very many organizations aiming to improve animal welfare and grant animals rights, because no matter how the industry spins it, factory farming can't be natural or humane. This business has turned beings into things, consumable goods, numbers, and profit. Non-human animals are individuals, just like any human being, with interests and desires of their own. Therefore there is no right way to kill someone who does not want to die. These organizations have a fundamental role in growing awareness and changing people's perception of the industry and its affects both on animals and consumers. Nevertheless what they lack is coordination and a common drive in vision and mission to achieve the overall cultural change. Who could steer the process, who can be entitled, who has the reputation to do so? We can build that body, we need to become those key people, we need to be the enablers, the innovators.

The approach does not have to be drastic, it's a day-by-day educational process. Couldn't we just start downsizing and "re-wilding" ourselves? And what does it mean? It 
means consuming, eating, producing less, and wasting no more; distributing equally, filling the inequality gap that has broadened and broadened, in recent years to the extreme. Just a small example: if you shorten each daily shower by one or two minutes you could save up to 600 litres of water per month. Likewise if you give up eating one hamburger per month you save more than four months of short showers. So we can do a lot by only slightly changing our habits in a step-by-step mode. We could also start getting out of our "cages", offices, buildings, houses, and start to feel our inner animal that craves for nature and connection to other animals. Nothing in nature lives for itself; rivers don't drink their own water, trees don't eat their own fruit. Living for others is the rule of nature. The environment is in us, not outside of us. We have built boundaries to keep all that is natural outside of our daily routine, apparently to forget who we are and what we were made for. We can't see that all living elements on this planet are interconnected, that what we do and keep doing to the environment we are inevitably doing it to ourselves and all living beings. In fact in our culture, the decisive political conflict, which governs every other conflict, is that between the animality and the humanity of man (Giorgio Agamben, The Open: Man and Animal, 2002).

No one can perceive as fair the world we live in. From whatever angle you look at it deprivation, prevarication, poverty, violence, inequality rule and justice is lacking. We have gone through the French Revolution, the Russian Revolution, the Chinese Revolution, and all sorts of revolutions. Still the cebus capuccinus (a small ape from Central and South America) has a better sense of equality and justice then we do. If you have any time take the opportunity to look at some of the studies - such as the ones by the Dutch ethologist and primatologist Frans de Waal - done on their social capabilities and sense of community. These small monkeys are a real inspiration, as their characteristics include conflict resolution, cooperation, inequity aversion, and food sharing, whilst humans accept inequality, keep conflicts running for centuries, accumulate but don't share too willingly. According to de Waal, by being more systemically brutal than Chimps and more empathic than Bonobos, we are by far the most bipolar ape. Our societies are never completely 
peaceful, never completely competitive, never ruled by sheer selfishness, and never perfectly moral (Frans de Waal, Our Inner Ape: A Leading Primatologist Explains Why We Are Who We Are, 2005).

Do we ever pose ourselves the right questions on how to make an impact on our dearest ones and our fellow peers to stimulate the cultural change? We should address ourselves and others some questions regarding our current behaviour and economical model, like: Why are bees dying by the billions? Why are bats dying by the millions? Why is the bird and wildlife population plunging? Which are the problems caused by toxic farming practices? Why are poachers so active as never before? What are the causes of soil and water depletion? Why are all living beings' rights being violated? And we could carry on forever...

I will leave the rest of the questions for you to meditate, but I shall analyze the first one about bees, at least some really good news about it. In March 2015 the chemical giant Bayer, in its attempt to sue Friends of the Earth Germany/BUND (Bund für Umwelt und Naturschutz Deutschland) over the NGO's claim that thiacloprid, an insecticide manufactured by Bayer, harms bees, has lost. Responding to last month's ruling by the court in Düsseldorf (Düsseldorfer Landgericht) that the environmental group had the right to voice its concerns, Friends of the Earth (England, Wales and Northern Ireland) bees campaigner Dave Timms said, "Bayer has been shown up as a corporate bully, trying to silence campaigners who are standing up for bees." ${ }^{4}$ People have taken action to protect bees across Europe but this is not what is happening in others continents where a very aggressive farming is causing severe soil depletion and plunge in wildlife populations. As far as the European Commission is concerned the action and step to be taken for the protection of all wildlife should be highlighted and empowered to ensure that any pesticide with evidence of harm to bees are taken off our shelves and out of our fields for good, not

\footnotetext{
4 Friends of the Earth, Chemical giant Bayer loses libel action over pesticide-harm claims <https://www.foe.co.uk/news/chemical-giant-bayer-loses-libel-action-over-pesticide-harm-claims>
} 
only in Europe but worldwide and stretched to all sorts of chemicals. To this regard what impact will the Transatlantic Trade and Investment Partnership (TTIP) between the European Union and the United States of America have? The official objective of the agreement is to improve regulatory coherence and cooperation and integrate the two markets by dismantling unnecessary regulatory barriers, differences in technical regulations, norms and approval procedures, standards applied to products, sanitary and phytosanitary guidelines. But in reality it implies a huge compromise for the EU, the standards of which are set much higher than the American ones. It implies a huge benefit for big corporations, a risk for health, safety and environment, and a thereat of large scale industrial agriculture to small scale producers, amongst many other issues. Just by comparing the irreconcilable differences regarding chemicals between the EU and the US, it is evident how this partnership undermines the possibility of a cultural change. ${ }^{5}$

\begin{tabular}{|l|l|}
\hline \multicolumn{1}{|c|}{ EU APPROACH } & \multicolumn{1}{|c|}{ US APPROACH } \\
\hline Intrinsic hazard emphasis & No emphasis on intrinsic hazard \\
\hline Precautionary principle & No precaution; damage than sue \\
\hline $\begin{array}{l}\text { Restricts chemicals (e.g. 1300+ from } \\
\text { cosmetics) }\end{array}$ & $\begin{array}{l}\text { Very few restrictions (e.g. 11 from } \\
\text { cosmetics) }\end{array}$ \\
\hline $\begin{array}{l}\text { Authorization process (ban) for industrial } \\
\text { chemicals of concern }\end{array}$ & $\begin{array}{l}\text { No authorization process (ban) for industrial } \\
\text { chemicals of concern }\end{array}$ \\
\hline $\begin{array}{l}\text { No-data, no-market } \\
85 \% \text { of chemicals enter the market with no } \\
\text { toxicity information }\end{array}$ \\
\hline Systematic prioritization and assessment & Ad-hoc prioritization \\
\hline Harmonized classification and labeling & It is up to industry to classify \\
\hline Burden of proof on industry & No meaningful burden on industry \\
\hline Public access to information (Aarhus) & No public access to information \\
\hline
\end{tabular}

\footnotetext{
${ }^{5}$ Humane Society International/World Animal Protection, An Eagle Eye on TTIP- Agriculture, research and sustainable development- what's on the horizon for TTIP? (2015).
} 


\section{dA derecho ANIMAL la web center de los animales con derecho}

A new economic model is an impellent necessity to size the needs of all the parts involved, take into account a redistribution of the scarce resources we have already squandered, and to establish a strict welfare and sustainability code. Profit cannot be the only driver; this must come to an end. Kalos kagathos. If what is handsome is also good, nature's response to human behavior will be the driving force of the cultural change. We will have to come to terms with nature and find the inspiration of becoming not the ruling force over it but the followers of its superior balance between all beings. It is love; love, the comfort of the human species, the preserver of the universe, the soul of all sentient beings, love, tender love (Volatire, Candide, 1759). 